\title{
O LEGISLATIVO VAI À ESCOLA: AS INSTITUIÇÕES POLÍTICAS E O PODER LEGISLATIVO NO ÂMBITO DA EDUCAÇÃO REGULAR
}

\author{
Marta Mendes da Rocha ${ }^{1}$ \\ Renata dos Santos Vieira ${ }^{2}$
}

Resumo: O artigo discute a participação política de jovens e a sua relação com a educação formal. Argumentando a favor do maior conhecimento e envolvimento dos jovens na política institucionalizada, buscou-se analisar as oportunidades abertas pelas normativas da educação e pelas inovações produzidas nos legislativos do país para a inclusão, no contexto da educação escolar, da temática das instituições políticas e do Poder Legislativo.

Palavras-chave: Participação política, Juventude, Instituições Políticas, Poder Legislativo, Educação para a Cidadania

\begin{abstract}
The article discusses the political participation of young people and their relationship with the formal education. Arguing in favor of greater knowledge and involvement of young people in institutionalized politics, the article aims to analyze the opportunities opened by education laws and by innovations produced by the legislatures of the country for inclusion, in the context of school education, of the theme of political institutions and Legislative Power.
\end{abstract}

Keywords: Political participation, Youth, Political institutions, Legislative Power, Education for Citizenship.

\section{Introdução}

Este artigo tem como objetivo discutir a participação política de jovens, seu envolvimento com as instituições formais da Democracia e o papel da educação formal para o

\footnotetext{
${ }^{1}$ Doutora e Mestre em Ciência Política pela Universidade Federal de Minas Gerais (UFMG). Professora da Universidade Federal de Juiz de Fora (UFJF). Pesquisadora, membro do Conselho Técnico-Científico do Centro de Estudos Legislativos da UFMG (CEL-DCP). (mendes_rocha@ yahoo.com.br)

${ }^{2}$ Licenciada em História pela Universidade Federal de Minas Gerais (UFMG). Aluna do curso de Especialização em Políticas Públicas na mesma instituição. Trabalha com projetos voltados para a defesa de direitos de crianças e adolescentes e pesquisa métodos e estratégias educacionais a serem aplicadas fora do contexto da educação formal (renatasv77@ yahoo.com.br).
} 
desenvolvimento juvenil das capacidades requeridas para o exercício da cidadania. Além disso, busca apontar algumas sugestões didático-pedagógicas para a inclusão, no contexto da educação escolar, da temática das instituições políticas, sobretudo do Poder Legislativo.

Os estudos sobre a participação política e social da juventude, no período posterior à redemocratização brasileira, são ainda recentes e escassos. Até a realização de pesquisas mais sistemáticas sobre o tema, a juventude brasileira tendia a ser classificada como apática, despolitizada e incapaz de reflexão crítica sobre seu ambiente político e social, em contraposição às gerações anteriores, marcadas por maior engajamento cívico (Florentino, 2008; Castro, 2009). Segundo Florentino, ter-se-ia produzido um modelo de comportamento juvenil baseado nos movimentos da década de 1960, segundo os quais os jovens carregariam consigo o potencial para a crítica e a transformação da realidade (2008, p. 209). Tal compreensão, no entanto, não levava em consideração as diferenças contextuais que marcaram a socialização e a atuação política da juventude da década de 1960 e as que caracterizam as gerações atuais.

Um ponto importante destacado por Florentino é o de que a geração atual de jovens nasceu e cresceu "num regime assumidamente democrático, que oferece certas vivências e oportunidades de socialização política distintas", ou seja, em um contexto radicalmente diferente do observado na década de 1960 (Florentino, 2008, p. 216). Como destaca a autora, a geração atual conta com uma legislação que garante os direitos individuais, entre eles, de expressão, reunião e de associação (inclusive, para organizações estudantis) e com a inexistência de censura dos meios de comunicação e da produção cultural (Florentino, 2008, p. 216-17). Os estudos mais recentes, considerando as especificidades do atual contexto, buscam compreender qual é a inserção real dos jovens nas sociedades contemporâneas, o que eles pensam, quais são suas expectativas e, em que medida, sua aparente indiferença e alienação podem ser compreendidas como desinteresse geral pela política. Nesse contexto, destacam-se duas pesquisas: a realizada em 2004 pelo Instituto Cidadania, e a pesquisa "Juventude Brasileira e Democracia", realizada pelo Instituto Brasileiro de Análises Econômicas e Sociais (IBASE) e pelo Instituto Pólis, no ano de 2005. ${ }^{3}$

Ambas as pesquisas mostram que apenas uma minoria dos entrevistados considera-se politicamente ativa ou envolve-se em atividades coletivas no bairro e na cidade. A maioria não confia nos partidos e acredita que os políticos não representam o interesse da população. Por outro lado, as pesquisas não autorizam a conclusão de que exista um desinteresse geral pela política entre os jovens, ao mostrar que a maioria deles busca se informar sobre política e mais

\footnotetext{
${ }^{3}$ A pesquisa "Juventude Brasileira e Democracia" (IBASE/POLIS) ouviu uma amostra de 8000 jovens com idade entre 15 e 24 anos, de oito Regiões Metropolitanas do país (Belém, Belo Horizonte, Brasília, Porto Alegre, Recife, Rio de Janeiro, São Paulo e Salvador).
} 
de 1/3 reconhece que a política "influi muito" em suas vidas (Abramo; Branco, 2005; Castro, 2008; Florentino, 2008). Segundo Castro (2008), a pesquisa do Instituto PÓLIS/IBASE evidencia também a ênfase dos entrevistados nas ações voluntárias e comunitárias, vistas como formas importantes e mais acessíveis de participação dos jovens.

Informações sobre alistamento eleitoral também não permitem concluir que haja uma indiferença geral dos jovens em relação à política. Dados do Tribunal Superior Eleitoral mostram que, entre 2002 e 2006, houve um aumento considerável no alistamento eleitoral em todos os estados da Federação. Florentino, considerando a relação entre o número de títulos de eleitor emitidos e o número de jovens que estavam em condições de requerer o título, observou que, em 2002, do total de jovens que podiam obter o título de eleitor, 31,6\% o fizeram; em 2006, 44\% da população jovem na faixa etária na qual o voto é facultativo recorreram aos TREs para obter o título de eleitor. Em apenas quatro Estados, houve redução do percentual de 2002 para 2006 (Florentino, 2008). De 2006 para 2010, houve uma redução de 6,18\% no número de eleitores entre 16 e 18 anos cadastrados no TSE. Esta foi a primeira vez que se registrou tal redução desde as eleições de 1998. Entretanto, não há como saber se a redução corresponde à realidade, já que o TSE não apresentou uma análise dos dados proporcionalmente ao número de jovens nessa faixa etária que poderiam requerer o título de eleitor.

Nas próximas seções, pretende-se discutir alguns achados de pesquisas mais recentes sobre juventude e participação política com o propósito de argumentar a favor do envolvimento dos jovens na política, por intermédio das instituições políticas formais. Além disso, objetiva-se discutir formas pelas quais a educação regular pode contribuir para aproximar os jovens das instituições políticas formais, sobretudo, do Poder Legislativo. Enfatiza-se a importância desse Poder na própria trajetória do Estado de Direito e da Democracia. Além disso, buscar-se-á mostrar como mudanças recentes na estrutura dos parlamentos abrem espaços para o envolvimento direto dos cidadãos na organização da agenda pública e no processo de tomada de decisões.

\section{Juventude e participação política}

Para os estudiosos do tema, as pesquisas mais recentes mostram que a propalada indiferença dos jovens em relação à política é, na verdade, uma negação das instituições formais, como parlamentos e partidos, e dos modos tradicionais de se fazer política (Castro, 
2008; Florentino, 2008). Por outro lado, evidenciam a valorização das formas mais espontâneas e informais de participação e de organização coletiva. ${ }^{4}$ (Florentino, 2008, p. 206).

A ênfase no voto como mecanismo central de participação política, a quebra dos vínculos partidários tradicionais e os frequentes escândalos de corrupção passariam aos jovens a ideia de um sistema político fechado em si mesmo, pouco aberto aos interesses, identidades e problemas característicos da juventude e pouco passível de modificação a partir da ação política da sociedade (Abramo; Venturi, 2000, p. 5; Castro, 2008).

A questão, portanto, estaria em explicar por que os jovens sentem-se tão distantes da política institucionalizada, vendo o sistema político fechado aos seus interesses, às questões e aos problemas que os afetam. Tradicionalmente, a não-participação tem sido compreendida, em diversas correntes da teoria democrática, como decorrente da falta de informação (Schumpeter, 1983), da ausência de recursos e de capacidades (Dahl, 1997; Santos, 2006), da frustração com os resultados produzidos pela Democracia, do sentimento de impotência (Pateman, 1981), e, mesmo, da satisfação em relação ao funcionamento do sistema (Huntington, 1968).

Além dessas variáveis, os estudiosos da relação entre juventude e participação política buscam compreender os fatores que explicariam a não participação especificamente entre os jovens. Nesse sentido, destacam a falta de identificação das novas gerações com organizações hierarquizadas e burocratizadas e a preferência dos jovens por experiências mais espontâneas, informais e não-convencionais (Inglehart, 1997), e a concepção diferente, entre a juventude, da própria política entendida como "política do cotidiano, de pequenas organizações, de grupos informais, especialmente ligados à área cultural" (Florentino, 2008, p. 232-233).

Como resultado da realização de pesquisas mais sistemáticas sobre o tema, observa-se, também, a defesa de uma nova forma de se compreender a aparente indiferença da juventude pela política. Para Florentino (2008), é necessário distinguir entre a apatia na forma de passividade e a apatia que expressa, na verdade, uma atitude crítica em relação às instituições políticas clássicas da Democracia e uma opção consciente por não participar pelas vias tradicionais (Florentino, 2008, p. 207).

Não se pretende negar que a política, da forma como é tradicionalmente praticada pelos partidos e políticos profissionais, possa parecer complexa e burocratizada aos olhos dos jovens e distante de seu dia-a-dia. Os frequentes escândalos de corrupção, no caso do Brasil, e a persistência de problemas históricos em áreas que afetam diretamente a juventude contribuem para disseminar a frustração e a decepção de jovens e adultos em relação ao sistema político e

\footnotetext{
4 Evidencia essa postura o crescimento das organizações juvenis ligadas à cultura, esporte, meio ambiente, partidos políticos e outros. No Brasil, tais organizações já se mostraram capazes de incluir temas e reivindicações na agenda política e impactar a própria organização do Estado e o cardápio de políticas públicas ofertadas.
} 
aos agentes públicos. Pesquisas realizadas com a população brasileira mostram que, a despeito do crescimento da adesão incondicional à Democracia, a desconfiança em relação às suas instituições basilares é disseminada entre todas as parcelas da população, incluindo os mais escolarizados (Moisés; Carneiro, 2008; Moisés, 2010).

Ao longo do século XX, foi tornando-se cada vez mais claro que a representação não é uma resposta suficiente para o problema da participação nas sociedades democráticas. É necessário, para se assegurar a representatividade e a responsividade dos governantes, criar formas alternativas de envolvimento dos cidadãos na política para além das eleições. Em resposta, observou-se, sobretudo nas últimas três décadas, a multiplicação de inovações no campo da participação política que buscam torná-la mais acessível ao cidadão, abrir novas oportunidades para a vocalização de suas preferências e para o monitoramento de seus representantes (Pateman, 1970; Sader, 1988; Dagnino, 1994; Alvarez, Dagnino; Escober, 1998; Young, 2000; Santos; Avritzer, 2000; Fung; Wright, 2002).

Sem negar as enormes contribuições que tais inovações têm oferecido para ampliar a participação política entre parcelas da população, até então excluídas, pretende-se, neste artigo, argumentar a favor do envolvimento dos cidadãos, sobretudo, dos jovens, na política que se faz por intermédio das instituições políticas formais. A própria Teoria Participativa da Democracia que, em momentos anteriores, tendeu a enfatizar a participação fora do sistema político, tem compreendido, mais recentemente, que o sucesso de alguns meios de participação direta dos cidadãos depende de determinada forma de interação com a representação política (Fung; Wright, 2003; Wampler; Avritzer, 2004; Avritzer, 2008). Ao rejeitarem e se retirarem da política produzida no âmbito das instituições formais, os jovens não estariam contribuindo para a alteração dos padrões que eles criticam, mas, ao contrário, para a sua consolidação. Além disso, ao se enfatizar a participação extrainstitucional em detrimento da participação via partidos e parlamentos, corre-se o risco de contribuir para a consolidação de uma estrutura marcada por dois espaços que não interagem e não se comunicam. Por isso, sem descartar a importância e a legitimidade da inovação e da participação fora das estruturas institucionais, aspira-se, neste artigo, ressaltar a necessidade de que os jovens conheçam e se envolvam também na política institucionalizada, como condição para que seus interesses, valores e demandas sejam inseridos na agenda pública e considerados por aqueles que tomam as decisões.

\section{Educação no Brasil: oportunidades e desafios da educação cidadã}

Os estudos sobre participação política tenderam, tradicionalmente, a enfatizar a escolarização como uma variável central para explicar os diferentes níveis de participação 
eleitoral e envolvimento dos cidadãos nas questões públicas. $\mathrm{O}$ argumento central é o de que as sociedades e os extratos sociais mais escolarizados tenderiam a mostrar maior interesse pelos assuntos públicos e maior disposição para a participação (Downs, 1957; Almond; Verba, 1965; Lipset, 1987).

Sem descartar completamente tal associação, estudos recentes chamam a atenção também para a importância de se avaliar a qualidade da participação, mostrando que o crescimento generalizado da adesão dos brasileiros à Democracia não tem sido acompanhado do crescimento da confiança em relação às suas instituições basilares em todos os níveis de escolaridade (Moisés; Carneiro, 2008; Moisés, 2010). ${ }^{5}$ Parece, portanto, que a exposição permanente a informações e muitos anos de frequência à escola não são suficientes para despertar nos indivíduos a consciência da importância da participação política e do envolvimento nas questões públicas. Uma variável fundamental a ser considerada seria a própria natureza da educação e dos conhecimentos e informações construídos e das práticas vivenciadas no processo de ensino-aprendizagem.

Considerando-se os princípios que orientam a educação no Brasil, questiona-se em que medida se pode afirmar que o sistema de ensino abre espaços e oportunidades para uma educação que combine os objetivos de informação e de formação, contribuindo para dotar crianças e jovens das capacidades requeridas para o exercício da cidadania. Indaga-se de que maneira as normativas educacionais permitem a inclusão da temática das instituições políticas na educação regular, mais especificamente, da estrutura, organização, funções e desempenho do Poder Legislativo.

As diretrizes para a elaboração da política nacional de educação estão estabelecidas na Lei de Diretrizes e Bases da Educação Nacional (LDBEN), promulgada no ano de 1996. Em decorrência dos desdobramentos dessas diretrizes, foram elaborados os Parâmetros Curriculares Nacionais (PCNs), publicados pela primeira vez em 1997, e o Plano Nacional de Educação, cuja última revisão data de $2010^{6}$. Juntos, esses documentos apresentam os principais princípios e diretrizes a serem observados na educação pública e privada do País e os objetivos e metas a serem perseguidos conjuntamente por Estado e sociedade.

\footnotetext{
${ }^{5}$ Pesquisa desenvolvida entre os anos de 2005 e 2009 pelo Núcleo de Pesquisa de Políticas Públicas da USP (NUPPS) e pelo Centro de Estudos de Opinião Pública da UNICAMP (CESOP), a partir de uma amostra representativa da população brasileira.

${ }^{6}$ O PNE encontra-se em tramitação na Câmara dos Deputados em uma Comissão Especial formada exclusivamente para a sua apreciação. A última ação registrada referente ao PL No 8.035/2010 foi a aprovação, em Plenário, de um requerimento de realização de audiência pública para debater a regulamentação do ensino privado com representantes de instituições ligadas à educação.
} 
A LDBEN define como educação os "processos formativos que se desenvolvem na vida familiar, na convivência humana, no trabalho, nas instituições de ensino e pesquisa, nos movimentos sociais e organizações da sociedade civil e nas manifestações culturais" (Art. $1^{\circ}$, Título 1). De saída, portanto, estabelece uma visão ampla da educação que não se restringe ao processo de ensino-aprendizagem no âmbito da escola.

No artigo $2^{\circ}$ da LDBEN, ressalta-se que um dos objetivos da educação é contribuir para o pleno desenvolvimento do educando e seu preparo para o exercício da cidadania, assegurando a vinculação da educação escolar com a prática social. O artigo 26 abre a oportunidade para a inclusão de novos temas no currículo escolar ao esclarecer que, apesar de os currículos do Ensino Fundamental e Médio terem uma base nacional comum, poderão ser complementados por uma parte diversificada, que deve levar em consideração as especificidades locais e regionais da sociedade, da cultura, da economia e da clientela (LDBEN, 2010). Ainda no parágrafo primeiro do referido artigo, a lei aponta que o ensino da língua portuguesa e o da matemática deverão compor o currículo obrigatório, acompanhado do conhecimento do mundo físico e natural, e da realidade social e política, especialmente do Brasil.

O artigo 27 da referida Lei registra que os conteúdos da Educação Básica deverão assegurar "a difusão de valores fundamentais ao interesse social, aos direitos e deveres dos cidadãos, de respeito ao bem comum e à ordem democrática" (LDBEN, 2010). No que tange ao Ensino Fundamental, o artigo 32 aponta, entre outras ações, a compreensão do sistema político como uma estratégia para a formação básica do cidadão. Esse objetivo é reafirmado nos PCNs, entretanto, não há menção explícita à inclusão do conhecimento do sistema e das instituições políticas no currículo escolar.

Em vários momentos, a LDBEN define como objetivo orientador do processo educacional, a formação de sujeitos críticos e autônomos, conhecedores da realidade política do País (Art. 26, LDBEN, 2010). Dessa forma, não apenas abre espaço para o tratamento das instituições políticas e do Poder Legislativo no contexto da educação regular, mas afirma ser essa dimensão, ainda que de forma implícita, fundamental para o alcance daquele objetivo. Entretanto, em nenhum momento, a LDBEN faz referência explícita ao Poder Legislativo ou à outras instituições políticas.

A LDBEN oferece as bases para a elaboração dos Parâmetros Curriculares Nacionais (PCNs) que, por sua vez, orientam a elaboração do Guia Nacional do Livro Didático. Todas essas normativas encontram-se alinhadas com a compreensão de que a educação deve promover o desenvolvimento integral do educando e prepará-lo para o exercício da cidadania. O processo de elaboração dos PCNs envolveu ampla discussão, em âmbito nacional, na década de 1990, do qual participaram docentes de universidades públicas e particulares de vários estados brasileiros, 
técnicos de secretarias estaduais e municipais de educação, fundações e centros de pesquisas. Sujeitos a revisões constantes, os Parâmetros apontam diretrizes para estados e municípios elaborarem suas propostas curriculares, dentro das normativas nacionais estabelecidas pela LDBEN.

Em 1998, foram publicados os Parâmetros Curriculares que tratam da inclusão de temas transversais que perpassam todas as disciplinas. $\mathrm{Na}$ abertura do documento, apontam-se, como objetivos da educação, a compreensão da cidadania, definida como participação social e política, assim como o exercício de direitos e deveres políticos, civis e sociais. Além disso, foram elencados seis temas transversais - Ética, Meio Ambiente, Pluralidade Cultural, Saúde, Orientação Sexual, Trabalho e Consumo.

Pautada no principio democrático, a política nacional de educação reconhece a heterogeneidade do território brasileiro e concede aos entes federativos autonomia para a inclusão de propostas educativas coerentes com as particularidades locais. Esse princípio proporciona, portanto, a oportunidade para a inclusão de outros temas, que podem ser tratados de forma interdisciplinar nas escolas, a partir da iniciativa dos docentes e da própria instituição de ensino, que possui autonomia para incluir e priorizar no currículo outros assuntos pertinentes.

A partir das diretrizes da LDBEN e com a articulação entre Ministério da Educação e educadores de todo o País, o currículo escolar adquiriu novo perfil, pautado na intersetorialidade e na interdisciplinaridade, além da inclusão de conteúdos considerados fundamentais para o desenvolvimento do educando. Tais princípios proporcionaram a inclusão da obrigatoriedade do estudo da cultura africana no Ensino Fundamental e Médio por meio da Lei n. 10.639, de janeiro de 2003. Outra evidência da flexibilidade, afirmada na LDBEN e nos PCNs, ocorreu por meio das Leis ns. 11.684 e 11.769, ambas de 2008, que estabeleceram a inclusão da Filosofia e da Sociologia como disciplinas obrigatórias no Ensino Médio, e da Música, em toda a educação básica.

A breve análise dessas duas normativas evidencia que o conhecimento da realidade política e social do Brasil e a compreensão dos processos históricos de transformação da sociedade são vistos como cruciais para a formação integral do educando. O preparo do educando para o exercício da cidadania aparece, em diversas passagens de ambos os documentos, como um objetivo prioritário a ser atingido. Curiosamente, há poucas referências, tanto na LDBEN quanto nos PCNs, às instituições políticas do País. Além disso, essa temática não aparece como um dos temas transversais afirmados nos PCNs. ${ }^{7}$

\footnotetext{
7 O novo Plano Nacional de Educação (PL No 8.035/2010) em apreciação em Comissão Especial da Câmara dos Deputados apresenta vinte metas a serem executadas no decênio 2011 a 2020 relacionadas à
} 
Sabe-se que o exercício da cidadania passa pela compreensão e pelo conhecimento do sistema e das instituições políticas e, também, dos espaços e mecanismos legítimos de representação e participação. Por essa razão, a temática das instituições, com destaque para o Poder Legislativo, deveria estar melhor explicitada como componente dos currículos escolares e como estratégia precípua ao alcance dos objetivos afirmados.

Uma oportunidade aberta pela LDBEN encontra-se na autonomia das escolas para desenvolverem projetos sobre temas e assuntos diversos e na possibilidade de inclusão de temas transversais nos currículos. Obviamente, a inclusão e o tratamento efetivo da temática das instituições políticas na educação regular, assim como dos demais temas transversais, são dificultados pelos problemas vivenciados pelos profissionais da educação. A despeito dos vários esforços feitos nas últimas décadas para universalizar a educação básica, superar a distorção idade-série e ampliar a qualidade da educação, ainda há muitos obstáculos a serem transpostos.

Entre esses obstáculos, que não são recentes na educação brasileira, os estudiosos destacam os seguintes: (a) a ausência de uma política de valorização do professor focada na melhoria dos salários, das condições de trabalho e em uma política de formação continuada; (b) os baixos salários que obrigam os docentes a enfrentar jornadas duplas ou triplas e, dessa forma, reduzem as possibilidades para formação e atualização desses profissionais; (c) a escassez de verbas para programas de formação de educadores e a desarticulação intra e interinstitucional nos programas de formação; (d) a desarticulação entre Ensino Superior, Fundamental e Médio; entre teoria e prática; entre conteúdo e método de ensino; (e) o predomínio da dimensão técnica em detrimento da humana e política; (f) o desprestígio dos cursos de licenciatura, considerados pouco relevantes ou secundários, o que redunda na desvalorização da profissão docente; $(\mathrm{g})$ a inadequação e/ou insuficiência dos recursos físicos, materiais, técnicos e didático-pedagógicos (biblioteca, computadores com internet, material didático, etc.) (Paini, Greco; Amblard, 2009; Gouvêa, 2006; Saviani, 2009; Fernandes; Paludeto, 2010).

Todos esses fatores geram empecilhos para que gestores e professores exerçam maior protagonismo na prática educacional, concebendo e implementando projetos inovadores que incluam novas temáticas, como as das instituições políticas, no processo de ensinoaprendizagem. A deficiência na formação continuada, a escassez de tempo e, sobretudo, a falta de motivação contribuem para difundir, entre os próprios docentes, a insatisfação e a desconfiança em relação às instituições democráticas. Diante desse quadro, reduzem-se os

universalização do ensino em todas as instâncias, ao aumento da dotação orçamentária obrigatória para a educação de 5 para $7 \%$, à valorização do magistério com metas para elaboração de plano de cargos e salários, entre outros assuntos. Entretanto, não trata dos conteúdos curriculares e dos temas que poderiam ser incorporados pelas escolas. 
incentivos para que os profissionais da educação se engajem em ações que possam atenuar essas impropriedades entre os jovens educandos.

\section{Inovações institucionais no Legislativo: possibilidades de interlocução com a escola}

Uma das características mais marcantes da Constituição de 1988 refere-se ao surgimento das instituições participativas. No Parágrafo Único do artigo $1^{\circ}$, afirma-se que "Todo o poder emana do povo, que o exerce por meio de representantes eleitos ou diretamente, nos termos desta Constituição". Tal aspecto reflete a grande efervescência associativa que marcou a década de 1970 durante o movimento pela democratização do País e a participação da sociedade no processo constituinte (Rocha; Prata, 2009).

Desde então, assistiu-se ao surgimento de uma série de novas formas de participação política destinadas a permitir aos cidadãos maiores oportunidades para a vocalização de suas preferências, para o monitoramento do comportamento de seus representantes e para o tratamento de questões da esfera privada na arena pública, nos interstícios eleitorais. Para muitos, tais inovações apontam um novo conceito de Democracia e de participação que recupera a dimensão do engajamento cívico, como condição fundamental para o aperfeiçoamento e consolidação da Democracia (Santos; Avritzer, 2002). Os inúmeros estudos empíricos, produzidos nas últimas décadas, sugerem que as inovações institucionais apresentam um enorme potencial de transformação da estrutura política, de democratização das relações sociais e de disseminação de uma cultura de tolerância. Os estudos mostram que pelo envolvimento direto na política, os cidadãos podem influenciar a agenda pública, motivar a inversão de prioridades e promover maior justiça distributiva (Avritzer, 2003; Wampler; Avritzer, 2004). Entretanto, cada vez mais cientes das dificuldades enfrentadas nas arenas participativas, sejam elas institucionalizadas ou não, os estudiosos do tema vêm buscando, por meio de estudos comparados, investigar as condições que favorecem seu êxito e as que explicam o seu fracasso (Avritzer; Navarro, 2003; Fuks; Perissinotto, 2006; Faria, 2006; Avritzer, 2008; Coelho, 2007; 2010;).

Além das instituições participativas, destacam-se outras inovações que visam aproximar o cidadão da política, disseminar informações e dar mais transparência às ações dos agentes públicos de modo a ampliar a influência do cidadão comum e de capacitá-lo para o exercício de seus direitos. Nesse tocante, merecem destaque as inovações produzidas no âmbito do Poder Legislativo. Os legislativos brasileiros, com variações associadas ao grau de modernização e desenvolvimento institucional das casas legislativas, têm sido responsáveis pela realização de uma série de eventos abertos à participação da sociedade, entre os quais se destacam os 
seminários temáticos, os fóruns, as audiências públicas de comissões e a própria comissão de participação popular, presente em várias casas legislativas do País (Anastasia, 2001; 2009; Assis, 1997). Embora se diferenciem no tocante à sua periodicidade e institucionalização, todas essas instituições incluem entre seus objetivos permitir maior influência dos cidadãos e da sociedade organizada no processo de formulação, implementação e fiscalização das políticas públicas.

Uma das mais importantes prerrogativas das comissões permanentes é a de convocar audiências públicas para ouvir a opinião dos cidadãos, grupos e organizações da sociedade civil sobre assuntos de interesses próprios, relacionados ou não a algum projeto de lei. Essa prerrogativa, fixada nos regimentos internos de várias casas legislativas, ainda que não esteja diretamente relacionada ao processo decisório, funciona como uma forma de aproximar representantes e representados e, de dotar os legisladores de informações importantes sobre os interesses, as necessidades e objetivos dos diferentes grupos da sociedade civil.

A compreensão do real impacto da incorporação dos cidadãos e grupos da sociedade civil no processo decisório, entretanto, depende de um número maior de estudos comparados sobre a implementação de tais mecanismos de participação. A maioria dos estudos, produzidos até o momento, investiga a relação entre participação, representação e informação no processo legislativo a partir do estudo de um ou dois casos de realização de fóruns, seminários e audiências públicas (Morello, 1999; Prata, 2007; Correa, 2008).

As escolas do legislativo (EL), hoje presentes em todas as assembleias estaduais do Brasil e em várias câmaras municipais brasileiras, vêm constituindo-se em um espaço de formação política, não apenas para os servidores e parlamentares, mas para a sociedade como um todo. Os programas de educação para a cidadania, comuns em várias ELs, promovem cursos, palestras e seminários sobre as regras de escolha dos membros do Legislativo, o processo de produção das leis, a estrutura organizacional do Legislativo, o processo orçamentário, entre outros. Além disso, realizam visitas guiadas às casas legislativas nas quais os cidadãos têm a oportunidade de conhecer a estrutura física do parlamento e presenciar o diaa-dia dos deputados e dos trabalhos legislativos. Aos propósitos deste artigo, interessa destacar que, em várias casas legislativas, jovens e professores de instituições de ensino privadas e públicas aparecem como público prioritário de tais ações (Cosson, 2008; Marques Júnior, 2008; Ribeiro, 2010).

Várias outras iniciativas de casas legislativas, associações da sociedade civil e outros órgãos públicos buscam ampliar a interlocução entre a sociedade e o Poder Legislativo e levar 
até alunos e professores informações importantes sobre a organização e o funcionamento deste Poder, além da vivência de experiências relacionadas ao mundo da política ${ }^{8}$.

Vale destacar o projeto Parlamento Jovem executado pela Câmara dos Deputados e por várias assembleias estaduais brasileiras, em parceria com universidades, escolas e outros órgãos responsáveis pela educação (Cosson, 2008). Embora possa variar quanto às regras para participação e dinâmica, a ideia inerente ao Parlamento Jovem é permitir aos estudantes de escolas públicas e privadas vivenciar o processo legislativo, a representação política e a liderança, oferecendo oportunidades para os jovens conhecerem a rotina dos trabalhos legislativos. Em geral, o Parlamento Jovem é direcionado a alunos do Ensino Médio. Seu correspondente para crianças e adolescentes do Ensino Fundamental é a Câmara Mirim, também em operação na Câmara dos Deputados desde 2006 e em outras casas legislativas pelo País. O desenvolvimento de tais propostas, com frequência, se apoia em materiais didáticos ricos em informação, elaborados em uma linguagem acessível e lúdica.

Além do Parlamento Jovem, a Câmara dos Deputados executa vários outros programas na área de Educação para a Cidadania como o denominado Missão Pedagógica no Parlamento, que visa oferecer aos educadores formação em educação para Democracia. Realiza, ainda, o Escola na Câmara, que consiste em uma visita guiada à Câmara dos Deputados, integrada a uma aula interativa com um especialista da Casa, dirigida a alunos do Ensino Médio das escolas da rede de ensino pública e particular do Distrito Federal. Viabiliza, também, o programa EstágioVisita de Curta Duração, que oferece a universitários de todo o país o acesso a conhecimentos relacionados ao funcionamento da Câmara e a à forma de atuação de seus representantes 9 .

Como destaca Marques Júnior (2008), a educação para a cidadania pode ser compreendida como:

Ação consciente e organizada do parlamento no sentido da capacitação e
qualificação dos diversos agentes envolvidos no exercício da democracia.
Parte, para tanto, do reconhecimento da exigência de determinadas
capacidades e competências para o melhor desempenho dos atores na arena
democrática, (...), mas de necessária convivência entre representação,
participação e deliberação política. Aponta as distinções e a
complementaridade entre informação e educação na construção dessas
capacidades e competências, bem como o papel a ser desempenhado por

\begin{abstract}
${ }^{8}$ Exemplos de tais projetos são o "Legislativo na Sala", lançado em 2011 por iniciativa da Câmara de Vereadores na cidade de Canguçu (RS); o projeto de extensão universitária "Política na Escola", desenvolvido pelo Instituto de Ciência Política da Universidade de Brasília desde 2003; O Projeto Escola, executado pelo Tribunal Regional Eleitoral no Mato Grosso do Sul.
\end{abstract}

9 Mais informações podem ser obtidas no site da Câmara dos Deputados: http://www2.camara.gov.br/responsabilidade-social/edulegislativa 
todos os poderes e órgãos públicos na promoção de um esforço educativo, compartilhado e articulado, em prol da cidadania e da democracia (Marques Júnior, 2008, p. 3).

Por último, é importante citar a experiência dos portais das casas legislativas na internet por meio dos quais se busca divulgar uma série de informações sobre a organização da Casa, o processo legislativo e o dia-a-dia dos parlamentares. Além disso, os sites têm sido utilizados como instrumento para disseminar informações sobre a educação para a cidadania. O portal da Câmara dos Deputados, que divulga textos sobre política, cidadania, democracia, processo legislativo e atuação parlamentar, com ilustrações em cores, recebe em média oito mil visitas por dia (www.plenarinho.gov.br). O reconhecimento da qualidade do trabalho foi obtido com a inscrição para o prêmio IBEST ${ }^{10}$ nas categorias infantil e educacional logo nos primeiros anos de sua criação. O portal também recebeu o reconhecimento internacional da rede Direitos Humanos e Cultura (DHNET), que premia as melhores páginas da internet em língua portuguesa. $\mathrm{O}$ sucesso da iniciativa inspirou outras casas legislativas brasileiras a investirem em seus portais na internet como forma de promover a educação para a cidadania e a aproximação entre as escolas e os Legislativos.

A percepção dos jovens de que o sistema político e a política tradicional não sejam espaços abertos à participação e à incorporação de novos temas desconsidera os esforços realizados na última década, no âmbito do Poder Legislativo, com o objetivo de aproximar a sociedade do processo legislativo, ampliar a influência dos cidadãos no processo decisório e disseminar informações sobre a organização e o funcionamento dos parlamentos. Acredita-se que tais ações, sobretudo aquelas que fazem da escola e dos professores parceiros fundamentais para envolver os jovens estudantes, sejam uma interessante oportunidade para levar para a sala de aula a temática das instituições políticas e do parlamento. Divulgar tais ações entre jovens e adultos é uma forma de levá-los a questionar arraigados preconceitos e equívocos associados ao Legislativo, geralmente visto como um espaço fechado às inovações e dominado por antigos padrões e formas tradicionais de se fazer política. Nos dias atuais, talvez seja mais correto ver essas arenas como espaços dominados por lógicas distintas que remetem simultaneamente ao novo e ao velho, ao obsoleto e ao inovador.

\section{Sugestões para o tratamento da temática das instituições e do Poder Legislativo no contexto escolar}

\footnotetext{
${ }^{10}$ Prêmio criado em 1995 para destacar trabalhos na rede mundial de computadores. Estabelece o ranking dos melhores sites em 40 categorias.
} 
Segundo Castro (2009), o fato de que os jovens, até atingirem a sua maioridade, estão alijados dos direitos políticos contribuiu para que a reflexão sobre política e juventude se orientasse apenas em direção à maneira como os jovens se prepararam para a atividade política na idade adulta. A autora critica esse conceito de socialização política que o situa na esfera do privado e percebe as experiências políticas vivenciadas na juventude como uma mera simulação. Castro sugere, ao contrário, que a juventude seja pensada como uma fase da vida, na qual o jovem vivencia a política de forma real, nas experiências coletivas, na família, na vizinhança, na escola, no grupo de amigos, etc. A socialização política, nesse sentido, não deveria ser vista como algo pré-político, mas como processo pelo qual os jovens constroem o próprio sentido da política.

A escola e a sala de aula, ao reproduzirem em seu interior os vários conflitos e embates próprios da vida em sociedade, podem permitir aos jovens educandos experiências significativas associadas à temática das instituições políticas. Com essa orientação, enfatiza-se uma das principais diretrizes que deveria nortear o tratamento do tema das instituições e do Poder Legislativo na escola: que as estratégias didático-pedagógicas envolvam a vivência de práticas reais, ao invés de simples transmissão de informações. Os espaços abertos, seja pelas normativas que regem a educação, seja pelas inovações institucionais das casas legislativas, podem converter-se em interessantes alavancas para fazer da escola e da sala de aula laboratórios de aprendizagem sobre as instituições políticas do País. É bom lembrar que a interdisciplinaridade é um dos princípios centrais da política educacional do Brasil. Sabe-se que sua efetividade, no entanto, depende de uma mudança na formação e na cultura dos professores e na criação de momentos de interação entre os professores de diferentes áreas do conhecimento.

As sugestões apresentadas, neste artigo, pretendem dar enfoque ao Poder Legislativo, por várias razões. Primeiro, percebe-se que o Legislativo e seus membros são os principais afetados pela crise de credibilidade que atinge várias instituições políticas. Muitas vezes, o Poder Legislativo é visto mais como um empecilho do que como uma garantia da liberdade e dos direitos. Dissemina-se na sociedade a ideia de que o Legislativo é a arena na qual a corrupção é mais frequente e que os parlamentos e seus membros não são importantes para a definição dos rumos futuros do país ${ }^{11}$. Tal percepção corresponde apenas em parte à realidade e

\footnotetext{
${ }^{11}$ Segundo uma pesquisa desenvolvida pelo Centro de Referência do Interesse Público da UFMG (CRIP) na qual foram ouvidas 2421 pessoas com 16 anos ou mais, no ano de 2008, as câmaras dos vereadores, a Câmara dos Deputados e o Senado Federal são vistas, respectivamente, em primeiro, segundo e quinto lugares como as arenas onde a corrupção é mais frequente. Pesquisa desenvolvida entre os anos de 2005 e 2009 pelo Núcleo de Pesquisa de Políticas Públicas da USP (NUPPS) e pelo Centro de Estudos de Opinião Pública da UNICAMP (CESOP), a partir de uma amostra representativa da população brasileira, mostra que $62 \%$ dos entrevistados afirmaram ter pouca ou nenhuma confiança no Congresso Nacional. Os
} 
desconsidera a grande importância histórica do Poder Legislativo, seja para a constituição do Estado de Direito, seja para a própria existência e sobrevivência da Democracia.

Os grandes avanços alcançados nas últimas décadas na área dos estudos legislativos no Brasil podem ser de grande valia na formação dos professores. Daí a importância de se reduzir o hiato entre o conhecimento produzido nas universidades e centros de pesquisa do País e o conhecimento construído (ou simplesmente transmitido) aos alunos em sala de aula. Além disso, destaca-se a necessidade de se disponibilizar aos professores materiais didáticos adequados e uma formação continuada que os permita desenvolver competências, habilidades e capacidades para o tratamento do tema.

Uma condição prévia, entretanto, é a de que entre os atores responsáveis pela educação sejam superados os equívocos e preconceitos relacionados à atuação do Poder Legislativo e seja reconhecida sua importância como arena representativa, garantia fundamental do exercício da liberdade e da democracia, e espaço considerado espaço privilegiado para o tratamento dos problemas e das questões sociais.

Como gestores educacionais e professores das diversas áreas do conhecimento podem se preparar para levar até a sala de aula e além de seus limites, conhecimentos, informações e experiências com foco no Poder Legislativo, sua organização e dinâmica? Para mostrar ser possível incluir a temática em todas as disciplinas do Ensino Fundamental e Médio, são apresentadas algumas sugestões a seguir.

No ensino de História é possível encontrar oportunidades claras para tratar o tema. O estudo das revoluções burguesas deixa evidente a importância dos parlamentos na derrocada das monarquias absolutistas e na constituição do Estado de Direito, no reconhecimento dos direitos fundamentais e na afirmação do princípio da igualdade política. Dentro dessa temática, é possível discutir a relação entre lei/regra, de um lado, e virtude, do outro. Uma forma de tornar a experiência mais significativa para os educandos é levá-los a estabelecer comparações entre a organização do Legislativo no passado e em nossos dias. Confrontar os métodos, antigo e atual, de escolha dos representantes e suas implicações no que se referem à inclusão e representatividade e comparar as prerrogativas dos parlamentos no passado, quando eram apenas órgãos consultivos, com os poderes que possuem na atualidade. Trata-se de uma oportunidade de discutir e diferenciar as funções dos parlamentares nas diferentes esferas de governo no Brasil. Os programas desenvolvidos pelas casas legislativas, em forma de visitas

deputados e senadores foram assinalados apenas por 1,8\% e os partidos políticos apenas por 1,4\% como instituições mais importantes "para o país seguir em frente". 
guiadas e palestras, são uma alternativa para tornar o tratamento da temática mais significativa para os alunos, levando-os a presenciar o processo decisório no plenário e nas comissões.

No ensino de Geografia, outra alternativa para se falar sobre o Poder Legislativo, é mostrar como a própria organização do território é objeto de luta política e tem no Legislativo uma arena privilegiada de decisão. Como exemplo, basta citar o debate atual em torno da reorganização do Estado do Pará. No tratamento das questões ligadas à ecologia e ao meio ambiente, pode-se mostrar como o Legislativo, nos últimos anos, em vários países, vem abrigando importantes debates em torno das formas de se conciliar desenvolvimento e preservação ambiental. A participação nas reuniões das comissões, voltadas para a apreciação de projetos de lei relacionados ao meio ambiente pode ser uma alternativa interessante para articular os currículos de Geografia, Ciências (no Ensino Fundamental) e Biologia (no Ensino Médio) e mostrar a importância crescente dessa agenda no Legislativo, nos últimos anos.

Temática importante no ensino de Geografia, cada vez mais em pauta no Legislativo, diz respeito às energias alternativas, ao uso dos recursos naturais e suas implicações para a preservação do meio ambiente. Levar para a sala de aula o debate, travado no Poder Legislativo, em torno da exploração do petróleo da camada do pré-sal e sobre as regras de ocupação e uso do solo, é uma forma interessante de demonstrar os efeitos das decisões políticas na regulação da relação entre o homem e seu ambiente.

$\mathrm{Na}$ Física também é possível abordar temáticas relacionadas ao sistema político, às instituições e ao Poder Legislativo. Uma discussão conceitual pode surgir da própria noção de "lei", que designa fenômenos diferentes na Física e no Direito, mas guarda semelhanças nos aspectos da regularidade e da previsibilidade. Não é coincidência o fato de que um dos principais momentos de ruptura na história da Física (o século XVI) também tenha sido um momento importante na constituição do Estado de Direito. A afirmação do humanismo e do racionalismo, em contraposição ao teocentrismo dos séculos anteriores, esteve na base dos dois processos. Tem-se mais uma oportunidade de tratamento conjunto de temas próprios da Física e da História e da trajetória do Poder Legislativo.

Na Química e em outras disciplinas da área das ciências da natureza é possível discutir a relação entre Ética e Ciência e a questão da regulação das pesquisas. As comissões de ciência e tecnologia, em várias casas legislativas do País, têm abrigado debates sobre tais questões e produzido regulação que orienta o desenvolvimento da pesquisa e a atuação dos pesquisadores.

$\mathrm{Na}$ Biologia, as noções de órgão e sistema e de relação do todo com as partes podem servir de base para abordar conceitos como "sistema político" e "órgãos decisórios".

Inclusive na Matemática, disciplina na qual aparentemente seria difícil encontrar laços com o tema do Poder Legislativo, é possível apontar várias alternativas. Encontra-se ali a 
oportunidade de discutir as diferentes acepções do termo maioria, empregadas nos processos decisórios no parlamento e suas implicações. Pode-se tratar dos diferentes métodos de transformação de votos em cadeiras legislativas e de distribuição de restos (assunto que poderia ser relacionado à noção de proporção). Ainda nesse âmbito, seria permitido discutir os métodos empregados para se definir a relação entre tamanho da população e número de membros das casas legislativas. $\mathrm{O}$ entendimento dos conceitos de maioria e de minoria empregados nas casas legislativas para designar agrupamentos políticos, pode ser confrontado com o dos preceitos matemáticos. As noções de limite, união e interseção podem ser utilizadas para se compreender a distribuição de atribuições e competências exclusivas e concorrentes entre os Poderes Executivo e Legislativo, a ideia de separação de poderes, o sistema de freios e contrapesos e a distribuição de competências e prerrogativas entre os entes federados. Por fim, as noções de receita, despesa e juros podem ser empregadas na compreensão do orçamento público.

No Português, pode-se discutir o novo acordo ortográfico que passou a vigorar no Brasil e em todos os países de língua portuguesa, em janeiro de 2009, com o objetivo de mostrar que as convenções linguísticas também são objeto de decisão política. A discussão em torno do uso de estrangeirismos e a tentativa de aboli-los por meio de um projeto de lei são outro exemplo de que as questões relacionadas à língua podem suscitar polêmicos debates. Os alunos poderiam, ainda, ser convidados a conhecer a estrutura de uma minuta de projeto de lei , a fim de conhecer a técnica legislativa empregada na elaboração de leis.

Por último, outra atividade, a ser desenvolvida em qualquer disciplina, é a comparação da organização legislativa com a própria organização escolar. Tal atividade poderia ser uma forma de empregar os conceitos de organização e instituição e alguns de seus atributos, tais como regras, postos de liderança, arenas decisórias, etc.

É claro que a prática das sugestões aqui apresentadas depende de motivação e capacitação dos docentes e dos gestores escolares e da presença de outras condições, que os permitam ir além da função informativa da escola. Implica em transformar em prática efetiva os princípios da interdisciplinaridade e a abordagem dos temas transversais presentes nas normativas que regem a educação no Brasil. Não se ignoram os inúmeros obstáculos vivenciados por gestores e professores em seu dia-a-dia. O que se pretende é contrapor a tais dificuldades as potencialidades oferecidas, seja pela autonomia dada às escolas pela LDBEN e pelos PCNs, seja pelas próprias inovações criadas no âmbito das casas legislativas em várias regiões do País. Acredita-se estar diante de uma interessante oportunidade de reinventar a prática pedagógica, em termos mais significativos para os alunos e com a incorporação de temas e problemas fundamentais à sua formação como cidadão. 


\section{Considerações finais}

O presente artigo pretendeu mostrar que as normas que orientam a educação no Brasil e as inovações promovidas pelos legislativos, nos últimos anos, abrem um caminho para o tratamento do tema das instituições políticas e do Poder Legislativo no âmbito da educação regular. Buscou-se apresentar algumas sugestões de como questões e temas próprios do dia-adia dos legislativos poderiam ser abordados na sala de aula, em várias disciplinas e áreas do conhecimento. Sem desconsiderar os vários obstáculos enfrentados pelos gestores educacionais e pelos docentes em seu dia-a-dia, acredita-se que uma maior interlocução entre Legislativo e escola poderia contribuir para o alcance dos objetivos afirmados na LDBEN e nos PCNs. Quanto ao papel social das casas legislativas, seria importante investir na divulgação dos projetos e mecanismos destinados a ampliar a interlocução com a sociedade e priorizar, cada vez mais, a escola, os gestores educacionais e os professores, como parceiros estratégicos para uma maior aproximação dos jovens. Em relação à função das escolas, além dos esforços no sentido de superar os problemas e obstáculos assinalados, é necessário criar condições para aumentar a criatividade dos docentes e investir cada vez mais em uma cultura de trabalho conjunto.

Acredita-se que uma maior interlocução entre o Legislativo e a escola pode contribuir para disseminar informações e conhecimentos importantes para fomentar a crítica produtiva e uma nova visão sobre o Legislativo, mais apurada e complexa. Para os jovens, é uma oportunidade de conhecer melhor as diferentes formas pelas quais é possível participar e influenciar o processo decisório. Dotados de tais informações e tendo desenvolvido certas capacidades necessárias ao exercício de seus direitos, os estudantes estarão mais aptos a, inclusive, apontar os limites das instituições formais e contribuir para a inovação política e a incorporação de novas questões à agenda pública.

\section{Referências}

ABRAMO, H.; BRANCO, P. (Orgs.). Retratos da juventude brasileira: análises de uma pesquisa nacional. São Paulo: Fundação Perseu Abramo, 2005.

ABRAMO, H.; VENTURI, G. Juventude, política e cultura. São Paulo: Fundação Perseu Abramo. Revista Teoria e Debate, n. 45, 2000.

ALMOND, G.; VERBA, S. The Civic Culture: political attitudes and democracy in five nations. Boston, Little. XEROX, 1965.

ALVAREZ, S.; DAGNinO , E; SCOBAR , A. Cultures of Politics, Politics of Cultures: Revisioning Latin American Social Movements. Boulder: Westview Press, 1998.

ANASTASIA, Fátima. Desenvolvimento institucional e representação democrática na ALMG. In: OLIVEIRA, Myriam Costa de (Org.) A Assembleia de Minas e a construção coletiva de 
políticas públicas: eventos institucionais, 1990-2009. Belo Horizonte: Assembleia Legislativa do Estado de Minas Gerais, 2009. 200 p.

ANASTASIA, Fátima. Transformando o Legislativo: a experiência da Assembléia Legislativa de Minas Gerais. In: SANTOS, Fabiano (Org.). O Poder Legislativo nos Estados: divergência e convergência. Rio de Janeiro: FGV Editora, 2001.

ANASTASIA, Fátima; INÁCIO, Magna. Democracia, Poder Legislativo, Interesses e Capacidades In: Câmaras Municipais e Prefeituras: Transparência, Controle e Participação Popular. Brasília: Câmara dos Deputados. (no prelo), 2006.

ASSIS, Luiz F. Educando para a cidadania: a experiência da escola do Legislativo. Educação \& Sociedade, ano XVIII, nº 59, PP. 367-385. 1997

AVRITZER, L. Sociedade Civil, Espaço Público e Poder Local: uma análise do Orçamento Participativo em Belo Horizonte e Porto Alegre. Relatório final do projeto Civil Society and Governance. DCP/FAFICH/UFMG, Mimeografado, 2000.

AVRITZER, L. O Orçamento Participativo e a teoria democrática: um balanço crítico. In: AVRITZER, L.; NAVARRO, Z. (Orgs.). A inovação democrática no Brasil: o orçamento participativo. São Paulo: Cortez, p. 13-60, 2003.

AVRITZER, L. Instituições participativas e desenho institucional: algumas considerações sobre a variação da participação no Brasil democrático. Opinião Pública, v.14 n.1 Campinas, junho, 2008.

BRASIL. Lei de Diretrizes e Bases da Educação Nacional. 5. ed. Brasília: Câmara dos Deputados, 2010.

BRASIL. Secretaria de Educação Fundamental. Parâmetros curriculares nacionais: introdução aos parâmetros curriculares nacionais. Brasília: MEC/SEF, 1997.

BRASIL. Brasil. Ministério da Educação e do Desporto. Plano Nacional de Educação. Brasília: Instituto Nacional de Estudos e Pesquisas Educacionais, 2011.

CASTRO, Lúcia R. Participação política e juventude: do mal-estar à responsabilização frente a destino comum. Rev. Sociol. Polít., Curitiba, v. 16, n. 30, p. 253-268, 2008.

CASTRO, Lucia R. Juventude e Socialização Política: Atualizando o Debate. Psicologia: Teoria e Pesquisa. Out-Dez, Vol. 25 n. 4, pp. 479-487, 2009.

COELHO, Vera Schattan P. et al. Mobilização e participação: um jogo de soma zero? Um estudo sobre as dinâmicas de conselhos de saúde da cidade de São Paulo. Novos estud. CEBRAP, n. 86, p.121-139, 2010.

COELHO, Vera Schattan P. A democratização dos Conselhos de Saúde: o paradoxo de atrair não aliados. Novos estud. - CEBRAP, n. 78, p.77-92, 2007.

CORREA, Izabela Moreira . Entre a representação e a participação: coordenação e competição na implementação da participação popular no ciclo orçamentário em Belo Horizonte e em Minas Gerais. Teoria e Sociedade, n. 16.2, julho-dezembro, p. 34-71, 2008.

COSSON, Rildo. Escolas do Legislativo, escolas de democracia. Câmara dos Deputados, Edições Câmara, 2008.

DAGNINO, E. Os movimentos sociais e a emergência de uma nova noção de cidadania. In: Os anos 90: política e sociedade no Brasil. São Paulo: Brasiliense, 1994.

DAHL, Robert A. Poliarquia: participação e oposição. São Paulo: EDUSP, 1997.

DOWNS, A. An economic Theory of Democracy. New York: Harper Collins Publishers, 1957. 
FARIA, Cláudia Feres. Fóruns participativos, controle democrático e a qualidade da democracia no Rio Grande do Sul: a experiência do governo Olívio Dutra (1999-2002). Opin. Publica, vol.12, n. 2, p.378-406, 2006.

FERNANDES, Angela Viana M.; PALUDETO, Melina Casari. Educação e direitos humanos: desafios para a escola contemporânea. Cad. Cedes, Campinas, vol. 30, n. 81, p. 233-249, mai.ago., 2010.

FLORENTINO, Renata. Democracia Liberal: uma novidade já desbotada entre jovens. Opinião Pública. Campinas, vol. 14, n. 1, junho, p.205-235, 2008.

FUKS, Mario; PERISSINOTTO, Renato Monseff; RIBEIRO, Ednaldo Aparecido. Cultura política e desigualdade: o caso dos conselhos municipais de Curitiba. Rev. Sociol. Polit. n. 21, pp. 125-145, 2003.

FUNG, Archon \& WRIGHT, E. O. (eds.). Deepening democracy: institutional innovations in empowered participatory governance (Real Utopias Project). London: Verso, 2003.

GOUVÊA, Giana R. R. Rumos da formação de professores para a Educação Ambiental. Educar, Curitiba, n. 27, p. 163-179, Editora UFPR, 2006.

HUNTINGTON, S. P. Political Order in Changing Societies. New Haven: Yale University Press, 1968.

INGLEHART, R. Modernization and Postmodernization. Cultural, Economic and Political Change in 43 Societies. Princeton: Princeton University, 1997.

LIPSET, S. El hombre político: las bases sociales de la política. Madrid: Tecnos, 1987.

MARQUES JÚNIOR, Alaôr M. Educação Legislativa: as Escolas do Legislativo e a função educativa do Parlamento. Belo Horizonte: Pontifícia Universidade Católica de Minas Gerais, 2008.

MOISES, José Álvaro; CARNEIRO, Gabriela Piquet. Democracia, desconfiança política e insatisfação com o regime: o caso do Brasil. Opin. Publica, vol.14, n.1, p. 1-42, 2008.

MOISES, José Álvaro. Os significados da democracia segundo os brasileiros. Opin. Publica., vol.16, n.2, p. 269-309, 2010.

MORELO, Jaqueline. Audiências Públicas Regionais: institucionalizando a participação no processo orçamentário de Minas Gerais. Belo Horizonte, 1999. 122 p.

NAVARRO, Zander. O Orçamento Participativo de Porto Alegre (1989-2002): um conciso comentário crítico. In: AVRITZER, L.; NAVARRO, Z. (Orgs.). A inovação democrática no Brasil: o orçamento participativo. São Paulo: Cortez, p. 89-128, 2003.

PAINI, Leonor D., GRECO, Eliana A. \& AMBLARD, Viviane M. L. A Formação de Professores no Brasil: Problemas e Perspectivas. Revista Eletrônica de Ciências da Educação. 2009. Disponível em: http://revistas.facecla.com.br/index.php/reped/article/view/543. Acesso em: 18 ago. 2011.

PATEMAN, C. Participation and Democratic Theory . Cambridge: Cambridge University Press, 1970.

PATEMAN, $C$. The Civic Culture: A Philosophic Critique. In: ALMOND, G.; VERBA, S. The Civic Culture: political attitudes and democracy in five nations. Boston, Little. XEROX, 1965.

POLIS-IBASE. Diálogo nacional para uma política pública de juventude. São Paulo: Instituto Pólis-Instituto Brasileiro de Análises Sociais e Econômicas, 2006. Disponível em: http://www.ibase.br/userimages/dialogo_juv_final21.pdf. Acesso em: 18 ago. 2011. 
PRATA, Nilson Vidal. Informação e democracia deliberativa: um estudo de caso de participação política na Assembleia Legislativa do Estado de Minas Gerais. Belo Horizonte, 2007, $162 \mathrm{p}$.

RIBEIRO, Guilherme W. Informação, aprendizagem e inovação nas Câmaras Municipais de Minas Gerais. Belo Horizonte. Pontifícia Universidade Católica de Minas Gerais, 2010.

ROCHA, M. M.; PRATA, Nilson Vidal. O Legado constitucional. Revista do Legislativo (Assembleia Legislativa do Estado de Minas Gerais), v. 42, p. 25-34, 2009.

SADER, E. Quando novos personagens entraram em cena: experiências, falas e lutas dos trabalhadores da Grande São Paulo (1970-1980). Rio de Janeiro: Paz e Terra, 1988.

SANTOS, Boaventura de Souza; AVRITZER, Leonardo. Para ampliar o cânone democrático. In: SANTOS, Boaventura de Sousa. (Org.). Democratizar a democracia: os caminhos da democracia participativa. Rio de Janeiro: Civilização Brasileira, p. 39-82, 2002.

SANTOS, Wanderley G. Horizonte do Desejo: instabilidade, fracasso coletivo e inércia social. Rio de Janeiro: Editora FGV, 2006.

SAVIANI, Demerval. Formação de Professores: Aspectos históricos e teóricos do problema no contexto brasileiro. Revista Brasileira de Educação. v.14. n. 40, 2009.

SCHUMPETER, Joseph A. Capitalismo, socialismo e democracia. Rio de Janeiro: Jorge Zahar, 1983.

WAMPLER, B.; AVRITZER, L. Públicos Participativos: sociedade civil e novas instituições no Brasil democrático. In: SCHATTAN, V.; NOBRE, M. (Orgs.). Participação e Deliberação: Teoria Democrática e Experiências Institucionais no Brasil Contemporâneo. São Paulo: Editora 34, p. 210-238, 2004.

YOUNG, I. M. Inclusion and Democracy . Oxford: Oxford University Press, 2000.

Artigo recebido em: 05/09/2011

Artigo aceito para publicação em: 19/10/2011 